\title{
A COLLABORATIVE PROFESSIONAL DEVELOPMENT MODEL: PROMOTING SHIFTS IN CLASSROOM PRACTICE
}

\author{
Pavneet Kaur Bharaj \\ Indiana University Bloomington \\ pkbharaj@iu.edu \\ Jinqing Liu \\ Indiana University Bloomington \\ jinqliu@iu.edu
}

\author{
Enrique Galindo \\ Indiana University Bloomington \\ egalindo@indiana.edu \\ Gina Borgioli Yoder \\ Indiana University - Purdue University Indianapolis \\ gbyoder@iupui.edu
}

To ensure conceptual learning in mathematics, teachers must shift many aspects of their instructional practices. We report on a two-year endeavor using a collaborative and responsive professional development model to help elementary school teachers enact seven shifts in classroom practice. We share evidence of teachers addressing the instructional shifts and discuss the promise of the approach used for those interested in co-constructing collaborations between and among universities and school districts.

Keywords: In-service Teacher Education; Professional Development; Instructional Leadership; Instructional Activities and Practices

\section{Purpose}

We report on a two-year professional development (PD) program designed to improve teachers' knowledge of mathematics, strengthen their pedagogical skills, and foster collaboration to reflect on practice and improve teaching. Guided by the Leading for Mathematical Proficiency Framework (Bay-Williams et al., 2014), this PD supported teachers' instructional shifts to better implement the Standards for Mathematical Practice (CCSSO, 2010). As part of the PD team, we (authors) implemented cycles of a "responsive and emergent" curriculum (Confrey \& Lachance, 2000, p. 244) to ascertain teachers' thinking and address their needs. We offered multiple, collaborative opportunities for participants to revisit and reflect upon their teaching practices, as they aimed to implement at least some of McGatha and Bay-William's (2013) seven instructional shifts (see Table 1).

Figure 1: Shifts in Classroom Practice (Bay-Williams et al., 2014, p. 24)

Shift 1 From same instruction toward differentiated instruction

Shift 2 From students working individually toward community of learners

Shift3 From mathematical authority coming from the teacher or textbook toward mathematical authority coming from sound student reasoning

Shift 4 From teacher demonstrating 'how to' toward teacher communicating 'expectations' for learning

Shift 5 From content taught in isolation toward content connected to prior knowledge

Shift 6 From focus on correct answer toward focus on explanation and understanding

Shift 7 From mathematics-made-easy for students toward engaging students in productive struggle

These seven shifts support teachers in creating a classroom culture where students are active participants in the learning process, namely: differentiating instruction, having students work as a community of learners, affirming mathematical authority comes from sound student reasoning, 
communicating clear expectations for learning, connecting content to students' lived experiences and prior knowledge, focusing on explanation and understanding, and engaging students in productive struggle. Our research question was: In what ways has the collaborative and responsive professional development model impacted teachers' shifts in classroom practice?

\section{Theoretical Underpinnings}

Change theory (Fullan, 2006) highlights the significance of stakeholders' democratic participation in a continuous and deliberate process to support a shift from existing towards new practices. Underwood (2015) acknowledged the contribution of professional learning communities to encourage teachers to re-think, re-learn, and re-engage with others as they articulate and process the meaning(s) of new practices. The PD team also realized the importance of building trust, acknowledging teachers' opinions and needs, and being willing to rethink our own practices. Therefore, we designed an iterative process, what we call the Collaborative and Responsive Professional Development (CRPD) model, to continuously and deliberately build trust, hear/see teachers' ways of thinking and knowing, and utilize this information to design meaningful experiences for the teacher participants.

\section{Methods}

\section{Participants and Setting}

The CRPD model emerged from a two-year partnership between a higher education institution and two school corporations. Participants were 60 elementary teachers (Grades K-6) from eight schools. The year-round PD support included: summer workshops, two full-day workshops (one in the Fall and one in the Spring), and four after-school workshops (two in the Fall and two in the Spring).

In this partnership, the PD team included two mathematics educators, one mathematician, one math coach, and two mathematics education graduate students. The full-time math coach was an experienced master elementary and middle school mathematics teacher. This arrangement of the PD model bridged the gaps between the PD team and the teacher participants as the mathematics coach proactively brought the teachers' voices to the planning sessions and helped to translate the projects' goals into meaningful and relevant learning activities for the teachers.

During PD sessions, the teachers were encouraged to work with others from the same grade level across schools and same-school participants from different grade levels so that they can benefit from the experiences of others and continue their interactions during the school year as a community of learners (Wenger, 1998, 2000).

\section{Data Sources and Analysis}

Data sources included an initial teacher inventory of classroom practices and teachers' annual selfreports on their instructional practices, self-assessed mathematics proficiency, and their experiences in professional development. The annual self-reports were a deliberate effort to understand the goals teachers had set for making shifts in their practice, capture their thinking about any shifts they had accomplished, and ascertain what shifts they still sought to make. The data comes from teachers' responses to the prompt: 'Have you noticed any changes in your math classroom, your students, or yourself? Could you describe them or share some specific examples?' Analyzing cases for which we had all data for two consecutive years $(\mathrm{N}=20)$.

We used thematic coding analysis (Braun \& Clarke, 2006) for coding the teachers' written responses with the seven shifts as the main themes. First, two authors collaborated to code each teacher's response according to whether and how it provided evidence of any of the seven shifts in classroom practice (Figure 1). To ensure a consistent understanding of the coding process, first, both coders worked together to code the first five cases from both years' data. Then, once an established 
coding system was developed each author separately coded the remaining teachers' responses. Those two authors came back together to discuss their respective codes and reconcile any differences. Those reconciled codes were shared with the other two authors, any differences were discussed, and again, reconciled to get agreement on $100 \%$ of the cases.

\section{Results}

To capture a holistic picture of how the teachers claimed to have shifted their classroom practices, we examined the distribution of the percentage of teachers whose responses referred to a specific shift (Figure 2).

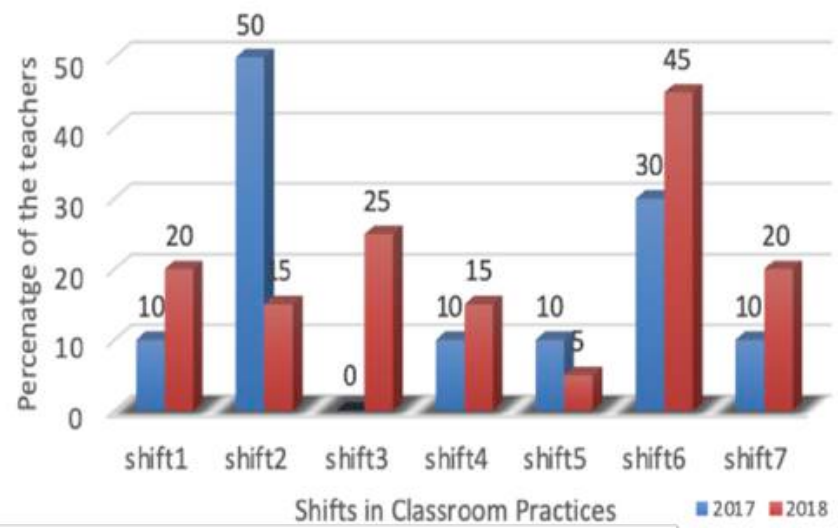

Figure 2: Distribution of Teachers' Self-Reported Shifts in 2017 and 2018

Over the two years, this group of teachers had shifted their instruction in each of the seven ways described by McGatha and Bay-William's (2013). However, two of the shifts (Shifts 2 and 6) stood out in our analysis, as they were mentioned substantially more often by the teachers. Shift 2, towards creating a community of learners, was mentioned by $50 \%$ of the teachers in year 1 . Shift 6 , towards a focus on explanation and understanding, was mentioned by $30 \%$ of the teachers in year 1 and $45 \%$ in year 2.

Regarding Shift 2, one teacher mentioned, "My students love when it is math time and how they get to share what they did to solve the problem because more than likely it is different than their neighbor's ideas!" (Teacher\#6, 2017). Teachers' responses reflected that being engaged in the activities around collaboration influenced their learners' listening, comprehending, accepting, and critiquing multiple ways of mathematical reasoning and thinking. Regarding Shift 6 teachers reported, "Students are stating their claims as 'I agree with.... because' or 'I disagree with ...... because' (Teacher\#7, 2018), which illustrates students recognizing the significance of using reasons to validate mathematical arguments.

Evidence for Shift 1, toward differentiated instruction, came from many teachers endorsing Math Workshop and Number Talks, as they realized that those instructional practices assisted them in recognizing specific strengths and gaps in their learners' mathematical thinking and guided them in designing appropriate next step instructional activities. While in yearl none of the teachers mentioned Shift 3, toward mathematical authority coming from sound student reasoning, teachers realized that by sharing their mathematical authority with other collaborators in learning, they could positively contribute to their students' learning. For example, one of the teachers stated:

During math, the kids are the ones that do the teaching. I serve as a guide. Instead of me making sure everybody is doing everything absolutely correct, I am able to sit back and let the kids make mistakes and explore and that's awesome (Teacher\#18, 2018). 
For Shift 4, toward teachers communicating expectations for learning, teachers started to see that transparency of the instructional objectives and flexibility in accepting various entry or exit points from the learners helped develop a sense of ownership in their students. One teacher mentioned, "mathematics is ... more about the process and thinking rather than the right answer" (Teacher\#2, 2018). Only a small number of teachers referred to Shift 5, toward content connected to prior knowledge, which might suggest that any change in this shift requires a longer period of instruction and training. Regarding Shift 7, engaging students in productive struggle, teachers realized that changes in their teaching style could help their students' perseverance. One of the teachers shared a success story of her student who did not like math in the early grades, however, made significant gains and contributed often to on-going mathematical class discussions (Teacher\#21, 2018).

When examining the distribution of the percentage of the teachers whose responses referred to a specific shift (Figure 2), we found that in general teachers' reports of enacting a specific shift in teaching increased for five of the seven shifts. While there was a decrease in the number of reports of addressing Shift 2, we do not think this necessarily means that teachers were not giving attention to this shift as work on the other shifts implicitly shows they are giving attention to this one. A similar pattern was observed for Shift 5, content connected to prior knowledge. We assume that initially the teachers might have been focusing more on their pedagogical orientation rather than on curricular materials while employing new instructional techniques in their teaching. However, we believe that with the passage of time subtle differences in their content and curricular knowledge will also be visible.

One limitation of this study is that the data sources are self-reports of teachers' perceptions of change in their instructional practices. We tried to minimize the impact of using self-reports by corroborating classroom shifts with the mathematics coach's observations in the teachers' classrooms.

\section{Discussion and Implications}

Research has shown that many reform efforts result in existing classroom practices remaining unchanged because it is difficult to shift mathematics understandings, attitudes, and experiences (Ball, 1996; Tzur et al., 2001). Researchers also offer that "professional development that is embedded in daily classroom practices of teachers in which there is a continuous loop of observation, feedback, and discussion in order to sustain learning" (Underwood, 2015, p. 26) helps in developing new capacities to sustain changes in instruction gradually. We are encouraged by the fact that teachers in this PD created achievable learning targets for their students by attending to their needs, interpreting their understandings, and creating opportunities to develop as mathematical doers and thinkers. We think that the shifts reported by the teachers will gradually lead them towards implementing the mathematical practices in their classrooms (Kilpatrick et al., 2001; National Council of Teachers of Mathematics, 2000).

We think this study provides some evidence of the feasibility of facilitating shifts in teachers' practices when professional development is centered on teachers' needs and engages the teachers in ways that we expect them to teach their students. The opportunities afforded by the processes of the Collaborative and Responsive Professional Development (CRPD) model show the potential of promoting teachers' effective shifts in mathematics teaching.

\section{References}

Ball, D.L. (1996). Teacher learning and the mathematics reforms: What we think we know and what we need to learn. Phi Delta Kappan, 77, 500-508.

Bay-Williams, J. M., McGatha, M., Kobett, B. M., \& Wray, J. A. (2014). Mathematics coaching: Resources and tools for coaches and leaders, K-12. New York: Pearson Education, Inc. 
A collaborative professional development model: promoting shifts in classroom practice

Braun, V., \& Clarke, V. (2006). Using thematic analysis in psychology. Qualitative Research in Psychology, 3(2), $77-101$

CCSSO (Council of Chief State School Officers). (2010). Common core state standards. Retrieved from http://www.corestandards.org/Math/.

Confrey, J., \& Lachance, A. (2000). Chapter 10: Transformative teaching experiments through conjecture-driven research design. In Lesh \& Kelly (Eds.), Handbook for design research in mathematics and science education (pp. 231-266). New York: Lawrence Erlbaum.

Fullan, M. (2006). Change theory. A force for school improvement. Jolimont, Victoria: Centre for Strategic Education.

Kilpatrick, J., Swafford, J., Findell, B., \& Mathematics Learning Study Committee, National Research Council. (2001). Adding it up: Helping Children Learn Mathematics. Washington, DC: Author.

McGatha, M. B., \& Bay-Williams, J. M. (2013). Making shifts toward proficiency. Teaching Children Mathematics, 20(3), 162-170.

National Council of Teachers of Mathematics (NCTM). (2000). Principles and standards for school mathematics. Reston, VA: Author.

Tzur, R., Simon, M.A., Heinz, K., \& Kinzel, M. (2001). An account of a teacher's perspective on learning and teaching mathematics: implications for teacher development. Journal of Mathematics Teacher Education, 4, 227-254.

Underwood, E. M. (2015). Teacher perceptions on changing instructional practices in mathematics with the implementation of the common core state standards. (Master's Thesis). Available from Dominican University of California Master's Theses and Capstone Projects.

Wenger, E. (1998). Communities of practice: Learning, meaning, and identity. Cambridge, UK: Cambridge University Press.

Wenger, E. (2000). Communities of practice and social learning systems. Organization, 7(2), 225-246. 